\title{
Extending Spatial Interaction Models with Agents for Understanding Relationships in a Dynamic Retail Market
}

\author{
Mark Birkin and Alison Heppenstall \\ School of Geography, University of Leeds, Leeds LS2 9JT, UK \\ Correspondence should be addressed to Mark Birkin, m.h.birkin@leeds.ac.uk \\ Received 20 August 2010; Accepted 17 January 2011 \\ Academic Editor: Michelle Thompson-Fawcett
}

Copyright ( $) 2011$ M. Birkin and A. Heppenstall. This is an open access article distributed under the Creative Commons Attribution License, which permits unrestricted use, distribution, and reproduction in any medium, provided the original work is properly cited.

\begin{abstract}
For many years, effective model-based representations of the dynamics and evolution of urban spatial structure have proved elusive. While some progress has been made through the deployment of spatial interaction models, these approaches have been limited by the difficulty of representing behavioural mechanisms and processes. In this paper, it is demonstrated that evolutionary models grounded in the principles of spatial interaction are compatible with the more novel approaches of agent-based modelling. The incorporation of agents provides a much more flexible means for the representation of behavioural mechanisms. The paper illustrates the way in which three more complicated situations can be handled through the fusion of spatial interaction and agent modelling perspectives. These situations comprise discontinuous evolution (in which structural adjustment takes place in discrete steps, and not as a continuously smooth process); nonequilibrium dynamics (in which the underlying system parameters continue to evolve through time); the incorporation of new decision variables (which we illustrate through the addition of land rents into the model). The conclusion of the paper is that the combination of spatial interaction and agent-based modelling methods provides encouraging prospects for the social simulation of real urban systems.
\end{abstract}

\section{Introduction}

In this paper, we set out to explore the relationship between two styles of modelling which have developed independently and have hitherto not been regarded as compatible. One of these is a well-established approach to simulating the dynamics and evolution of urban spatial structure. The other is a set of individual or agent-based models of spatial behaviour. In this introduction, we proceed to a recap on the origins of these approaches, and then discuss their compatibility.

There is a long tradition of representing the spatial relationships between retailers and their customers using spatial interaction models (original work of Huff, [1], was provided with solid mathematical foundations by Wilson, $[2,3]$; a summary of the model features is provided by Birkin and Clarke [4] while many empirical and commercial applications may be found $[5,6])$. The representation of dynamic relationships within these models has always been more difficult. A sound conceptual basis for this problem was provided by Harris and Wilson [7], who proposed a straightforward but appealing view of the characteristics of a network of retail interactions at equilibrium. The nature of the equilibrium networks was explored in further work of Clarke and Wilson [8], and the power of these ideas in the broader context of location theory was investigated in relation to residential location [9], industrial location $[10,11]$ and agricultural location [12]. Further insights into the dynamic behaviour of the models were available from dynamical systems theory [13].

Despite these strong theoretical foundations, real applications of the model are hard to find, with the partial exceptions of Wilson and Oulton (1983) and Clarke and Wilson (1986). In the first of these papers, the authors argued for a model-based understanding of the "cornershop to supermarket" transition in British retailing after the war [14], while the second paper introduced detailed evidence of retail patterns in Leeds, albeit with limited dynamics [15]. In part the issue here is undoubtedly one of data, but other important issues concern the level and quality 
of representation of retail systems within this framework. Specifically, the models are determined by an aggregate and limited notion of "floorspace" at a "location", while the dynamic mechanisms which suggest an overall balancing of costs and revenues seem to imply a somewhat unrealistic view of spatial competition in retail markets.

A much more popular recent approach to modelling systems with complex dynamics has been agent-based simulation [16, 17]. Such models assume that it is possible to represent complex systems in relation to the behaviour and interactions of individual decision-making entities (agents). These models have been applied with some success, for example, to problems involving transportation [18] and disease transmission [19]. In relation to economic markets the applications are quite diverse, ranging from game theory (e.g., the "El Farol bar problem" in which agents can only decide whether to visit their favourite bar by making assumptions about the likely presence or absence of other agents [20]) to stock market dynamics, in which markets are formed from the aggregate behaviour of individual decision-makers who may not only have different aims and objectives, but may even have varying levels of rationality [21]. Applications to geographical systems are less widespread although local models of crowd behaviour in public spaces or at specialised events, such as football matches or rock concerts, have been popular for some time [22] and there are the beginnings of some applications at the metropolitan scale [23]. Another interesting attempt to model dynamic retail markets with an agent-based framework is found in the work of Heppenstall et al. [24-26], in which the behaviour of petrol station managers was simulated as a population of interacting agents. An interesting feature of this work is a focus on price as a basis for competition, rather than size or market dominance as implied in the equilibrium models (see above). Nevertheless, despite a popular belief in the ability of agents to simulate the development of systems from the bottom up (or generative social simulation: $[27,28]$ ) agent simulations have been more convincing in portraying local dynamics than systemic behaviour.

In summary, the equilibrium-seeking mechanism of the Harris-Wilson model and related applications and the local dynamic interactions of the agent-based simulations appear to be complementary in a number of ways. While the former is largely focused on long-term, "slow" dynamics, the latter is much more oriented to short-term "fast" dynamics. The former focuses on floorspace as a basis for the adjustment; the latter has an emphasis on other factors, including prices. The former offers insights into the way a market might be trying to structure itself; the latter gives insights into how it might actually be getting there. For these reasons, we suggest that it might be useful to attempt the integration of these two styles of modelling.

The further development of this argument proceeds as follows. In the second section of the paper, we articulate a version of the Harris-Wilson model for an idealised geographical market. We then effect a rather coarse calibration of the parameters of a spatial interaction model in the HarrisWilson style to the West Yorkshire retail petrol market. In effect, therefore, the current status of the petrol market in
West Yorkshire is conceived as an equilibrium state from an adjustment of floorspace in accordance with the HarrisWilson rules. In the third section of the paper, we recast the same problem as an agent-based simulation. Now it is individual agents who make decisions about retail provision in relation to local market conditions. We demonstrate that if agents behave in the same way as the implied decisionmakers in Harris-Wilson, then the simulation results from these two methods are identical. Having achieved this, we suggest in Section 4 that the agent-based model provides an ideal platform for the extension and introduction of "added realism" to the Harris-Wilson model. We introduce a series of experiments to explore the effect of pricing strategy on spatial outcomes; the effects of covariation in price and floorspace adjustment; the effects of lumpy decision-making on retail dynamics.

Some discussion of the model results, concluding remarks, and suggestions for future research are provided in Section 5.

\section{An Equilibrium-Seeking Model of Retail Dynamics}

In this section, we establish a retail location model in which dynamic behaviour is driven by a competitive process leading to the elimination of surplus profits and a revenue-cost equilibrium. The analysis proceeds in three stages. First, we create an abstract representation of a spatial system and explore its equilibrium properties in a parameter space. Second, the representation is translated to a real geography in which petrol retailers compete for market share in the West Yorkshire area. Third, a means for the parametrisation of the "real world" model is described.

2.1. Abstract Geography. As a starting point, an idealised region was created with a square lattice of 729 zones, each separated from its horizontal and vertical neighbours by a distance of 1000 metres. Population is evenly distributed with 1,000 residents in each zone, creating an imaginary "city" approximately the size of Leeds. Each resident has an annual fuel spend of $\mathfrak{E} 100$. It is further assumed that fuel retailers can satisfy the demand for fuel by providing floorspace at a cost of $\mathfrak{£} 10$ per square metre. At the outset, 100 metres of retail space is allocated to each zone. The problem is how to simulate the changing distribution of retail space that satisfies both consumer demand and the laws of retail competition.

A solution to this problem can be found by following exactly the logic of Harris and Wilson (1978). Consumers are expected to behave in accordance with a productionconstrained spatial interaction model:

$$
S_{i j}=e_{i} P_{i} W_{j}^{\alpha} \exp \left(-\beta d_{i j}\right)
$$

in which $S_{i j}$ is the flow of expenditure from residential zone $i$ to retail zone $j$.

The scalars for expenditure $\left(e_{i}\right)$, population $\left(P_{i}\right)$, floorspace $\left(W_{j}\right)$, and distance $\left(d_{i j}\right)$ are all determined by the assumptions already outlined. The distance between 
each origin-destination pair is calculated as the straightline distance between zone centroids. The flow patterns will therefore vary in accordance with the two model parameters. Alpha $(\alpha)$ can be described as an "attractiveness factor" which mimics the effects of scale economies, so that with $\alpha$ greater than unity then large retail concentrations become more attractive to customers than small ones. Beta $(\beta)$ is described as a distance deterrence parameter: as $\beta$ increases, the preference of consumers to travel short distances rather than long distances becomes more pronounced.

For a given pattern of flows, the zonal revenues $\left(D_{j}\right)$ for retailers are determined by a simple summation:

$$
D_{j}=\sum_{i} S_{i j}
$$

The key step in the Harris-Wilson argument is then to assume progression towards an equilibrium condition which balances revenues and costs in each retail zone:

$$
D_{j}=k W_{j},
$$

where revenue exceeds cost, then retail supply expands to absorb market share, where cost exceeds revenue then supply contracts in an effort to reduce losses. The rate of expansion and contraction is controlled by a final model parameter, $\varepsilon$ :

$$
W_{j}(t+1)=W_{j}(t)+\varepsilon\left(D_{j}(t)-k W_{j}(t)\right) .
$$

Having already established the initial conditions for the model, the progression of the system through time can be simulated through a simple iterative process:

(i) calculate interactions (1),

(ii) calculate revenues (2),

(iii) update floorspace (4).

In the experiments which follow, the model is deployed for several hundred iterations. An equilibrium is assumed to have been achieved when for all retail zones there is a change in floorspace of less than $0.1 \%$ between successive iterations.

Now a series of experiments is conducted with varying combinations of parameter values for $\alpha$ and $\beta$. In Figure 1, equilibrium floorspace distributions are presented for combinations of $\alpha=(1.05,1.2,1.5)$ and $\beta=(0.2,0.5,1.0)$. The simulations have all been conducted with values for epsilon $(\varepsilon=0.05)$ which are small enough to guarantee a smooth progression towards equilibrium. The implications of higher rates of adjustment are considered further in Section 4.1 below. A set of results is obtained which parallels the earliest application of this method [8]. As scale economies are increased, then the number of "retail centres" is reduced; as the friction of distance goes up, the number of centres increases.

2.2. Real Geography. The next step is to develop the model from an abstract to a real geography. This is helpful for two reasons: first, that it is at least a small move in trying to develop and test the robustness of a conceptual model in a defined geographical system; second, it connects to previous work on the agent-based retail model which is introduced at Section 3 below.

For this work, West Yorkshire is taken as the study area. West Yorkshire is a Metropolitan District in the north of England, including the cities of Leeds and Bradford and with a total population in the order of 1.5 million people. The region was disaggregated into 127 census wards. Counts of population, households, and car ownership were taken from the 2001 Census of Population and Households. In the models, a fixed rate of expenditure of fuel ( $£ 10$ per week) has been adopted for each car based on figures drawn from consumer data [29]. Again it is assumed at the outset that 100 square metres of floorspace is provided in each retail zone at a cost of $\mathfrak{E} 10$ per square metre. (It is easy to demonstrate computationally that the unit cost of provision of floorspace ( $k$ ) does not affect the model outcome at equilibrium, as long as costs are not allowed to vary geographically. If the unit cost is reduced by half, then we simply end up with twice as much floorspace in the steady state.) The distance between zones is calculated as the straight-line distance between the population-weighted centroids of the origin and destination zones. (While it would be possible to introduce a more realistic transport network as well, this is not seen as a fundamentally important step in the current research. Ultimately everything depends on everything else: see for example, Birkin and Wilson [10], in the style of Ira Lowry's "Model of Metropolis." Such a project of generative simulation, to build an entire regional infrastructure from the bottom up, would be very much in the spirit of agentbased simulation, however. See discussion in Section 5.)

Results for this simulation are shown in Figure 2. It is useful to note in passing that the resulting distributions reflect to a reasonable degree the real pattern of retail provision in the West Yorkshire area. For example, in the simulation $(\alpha=1.05, \beta=0.2)$ the five peaks correspond fairly closely to the major urban centres of Leeds, Bradford, Wakefield, Huddersfield, and Halifax. This distribution is shown in the form of a more conventional map in Figure 3. Of course the lack of a complete correspondence is unsurprising. Although the patterns are determined by an actual distribution of population, the actual interzonal trip costs are heavily oversimplified by this model.

2.3. Parametrisation of the Model. In this section, we consider whether it is possible to assign values to alpha and beta which are to some degree representative of the underlying retail market. The term parametrisation is preferred to calibration, because of the number of simplifications in the model. This step is helpful in that in order to develop the simulations further a "pivot" will be required for the exploration of further model variants. It is logical to relate these variants to something realistic, rather than a completely arbitrary combination of parameters.

We proceed on the basis that there are two parameters to fix, therefore two metrics are required. An entropy-based measure of spatial dispersion has been defined which we expect to be related to the parameter alpha, and a distance measure representing consumer behaviour has been defined 
$\beta=0.2$
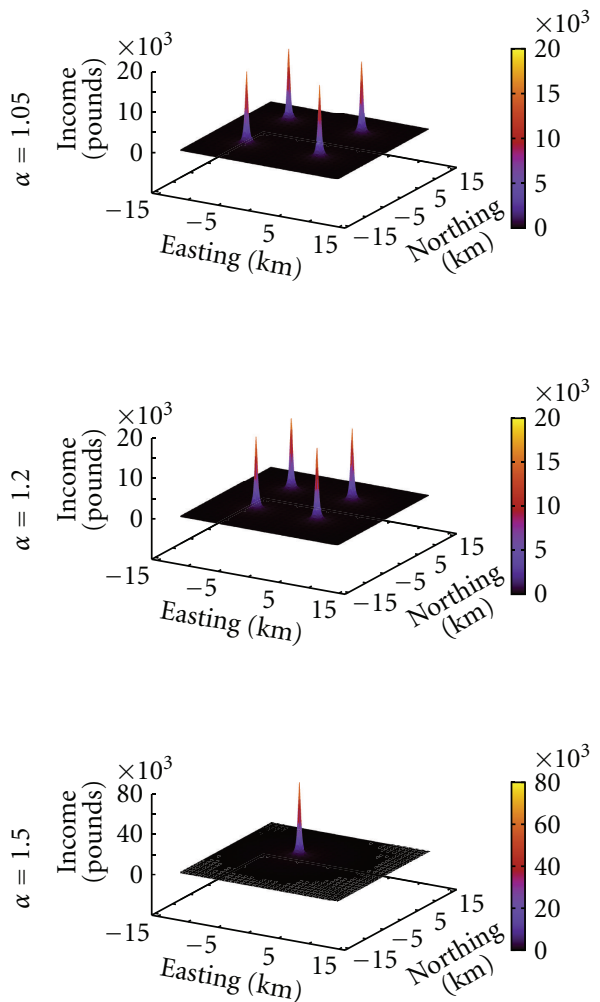

$\beta=0.5$
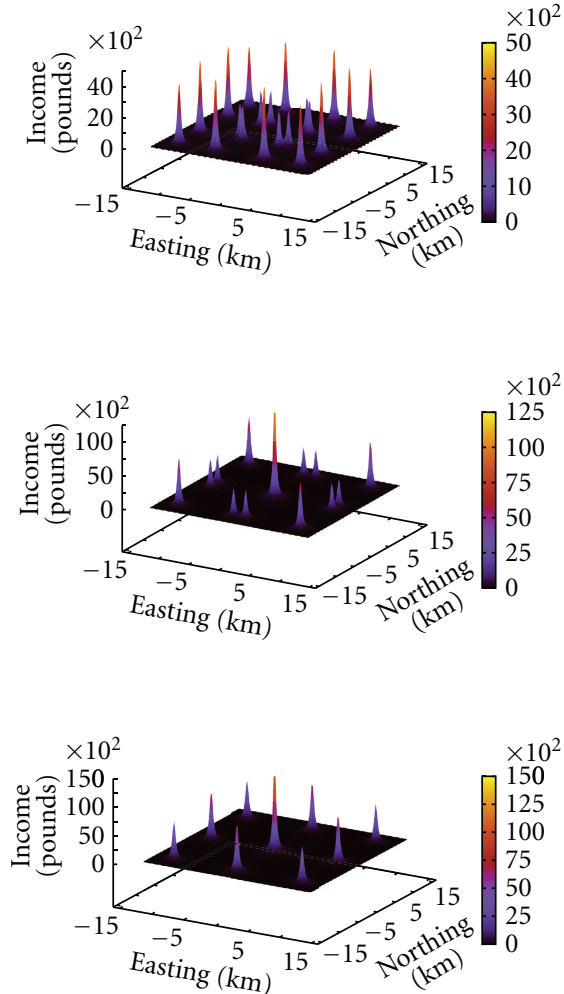

$\beta=1$
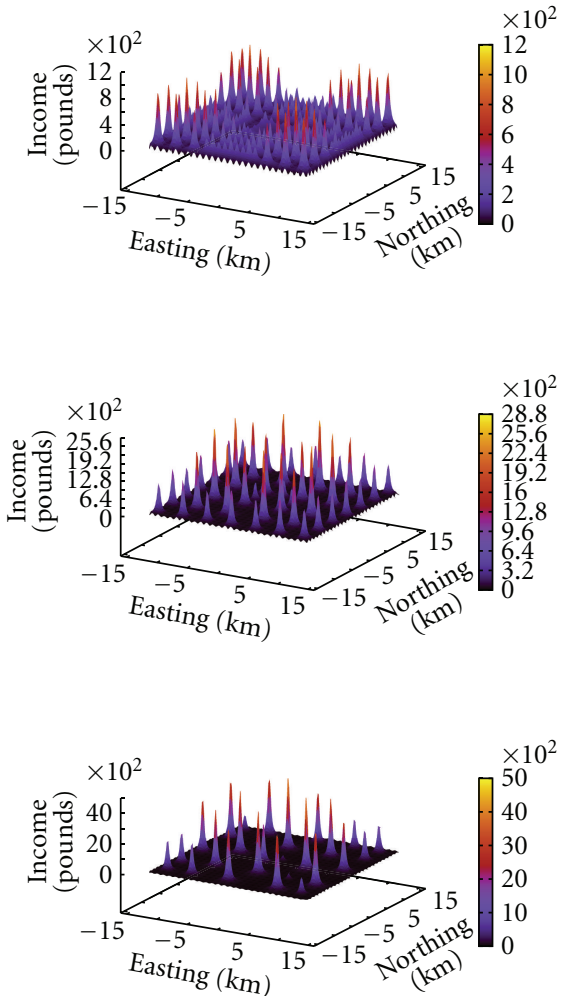

FIgURE 1: Equilibrium structures for an idealised geography.

$\beta=0.2$
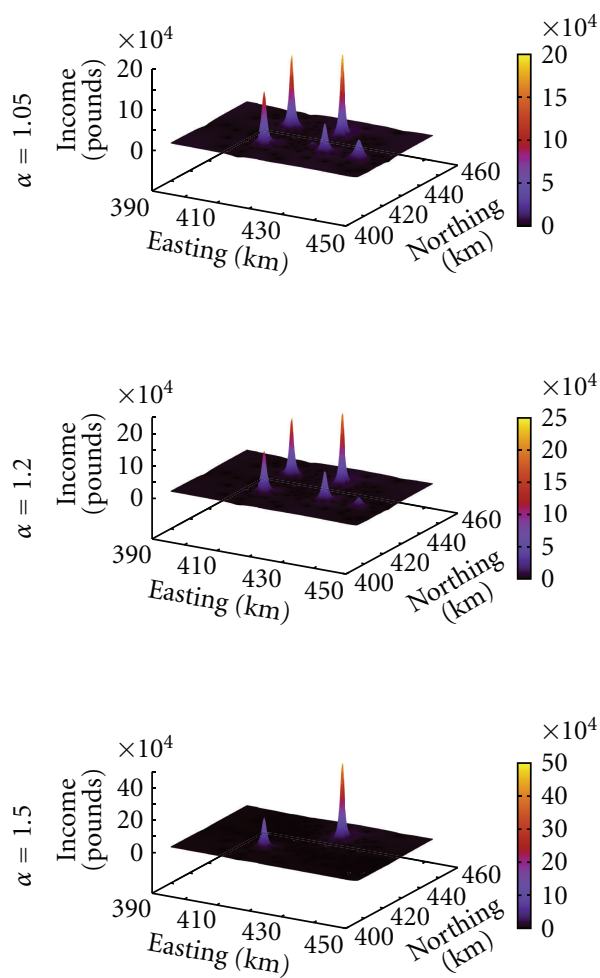

$\beta=0.5$
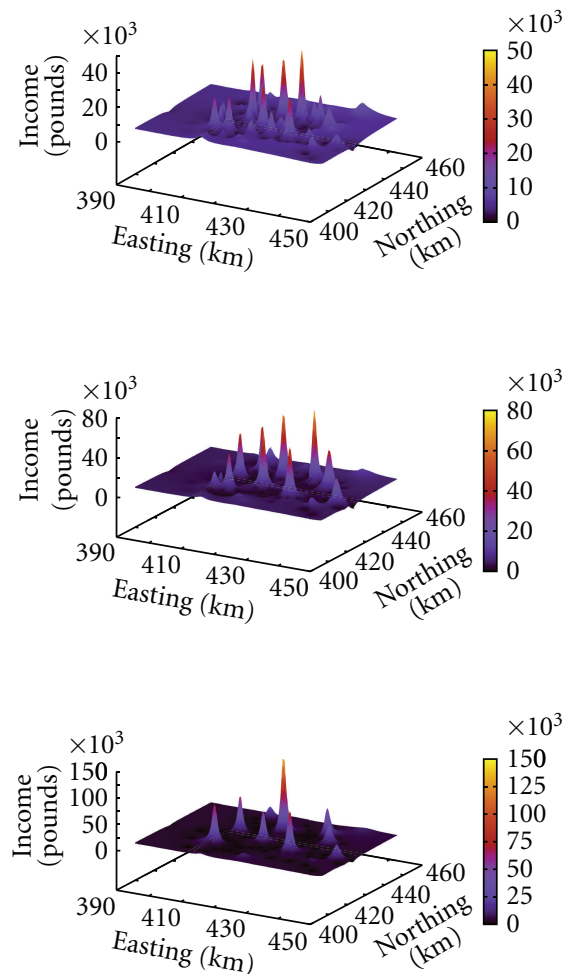

$\beta=1$
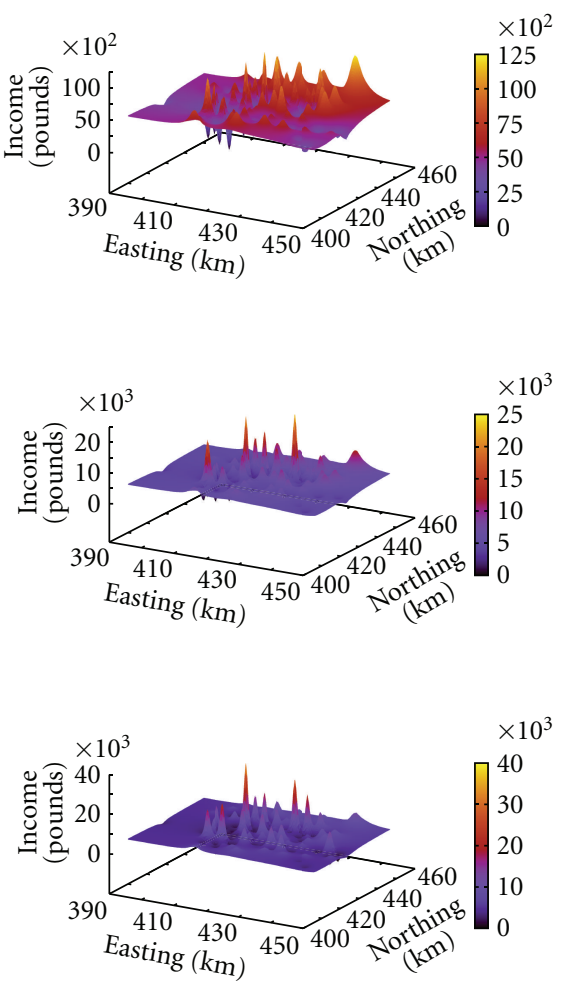

Figure 2: Equilibrium structures with a "real" geography. 
TABLE 1: Summary of fitness values from simulations.

\begin{tabular}{|c|c|c|c|c|c|c|c|c|c|c|}
\hline \multirow[t]{6}{*}{ First pass } & \multicolumn{5}{|c|}{ Average distance (rn) } & \multicolumn{5}{|c|}{ Entropy of dispersion } \\
\hline & \multicolumn{5}{|c|}{ Alpha } & \multicolumn{5}{|c|}{ Alpha } \\
\hline & Beta & 1 & 1.05 & 1.2 & 1.5 & Beta & 1 & 1.05 & 1.2 & 1.5 \\
\hline & 0.2 & 8315 & 8643 & 9085 & 12145 & 0.2 & 3.26 & 1.49 & 1.29 & 0.423 \\
\hline & 0.5 & 3178 & 3391 & 4036 & 5050 & 0.5 & 4.44 & 3.45 & 2.74 & 2.12 \\
\hline & 1 & 1245 & 1270 & 1444 & 1958 & 1 & 4.81 & 4.68 & 4.29 & 3.64 \\
\hline \multicolumn{11}{|c|}{ Second pass } \\
\hline & \multicolumn{4}{|c|}{ Alpha } & & \multicolumn{4}{|c|}{ Alpha } & \\
\hline & Beta & 1 & 1.02 & 1.05 & & Beta & 1 & & 1.02 & 1.05 \\
\hline & 0.5 & 3178 & 3236 & 3391 & & 0.5 & 4.44 & 3.89 & 3.45 & \\
\hline & 0.6 & 2512 & 2560 & 2647 & & 0.6 & 4.58 & 4.21 & 3.87 & \\
\hline & 0.7 & 2041 & 2074 & 2145 & & 0.7 & 4.69 & 4.44 & 4.19 & \\
\hline & 0.8 & 1695 & 1711 & 1762 & & 0.8 & 4.75 & 4.64 & 4.42 & \\
\hline & 0.9 & 1439 & 1448 & 1477 & & 0.9 & 4.79 & 4.74 & 4.58 & \\
\hline & 1 & 1245 & 1249 & 1270 & & 1 & 4.81 & 4.79 & 4.68 & \\
\hline \multicolumn{11}{|l|}{ Third pass } \\
\hline & \multicolumn{4}{|c|}{ Alpha } & & \multicolumn{4}{|c|}{ Alpha } & \\
\hline & Beta & 1 & 1.01 & 1.02 & & Beta & 1 & & 1.01 & 1.02 \\
\hline & 0.6 & 2512 & 2530 & 2560 & & 0.6 & 4.58 & 4.41 & 4.21 & \\
\hline & 0.62 & 2406 & 2421 & 2447 & & 0.62 & 4.61 & 4.46 & 4.27 & \\
\hline & 0.64 & 2306 & 2320 & 2343 & & 0.64 & 4.63 & 4.49 & 4.32 & \\
\hline & 0.66 & 2212 & 2226 & 2247 & & 0.66 & 4.65 & 4.53 & 4.36 & \\
\hline & 0.68 & 2124 & 2137 & 2157 & & 0.68 & 4.67 & 4.56 & 4.4 & \\
\hline & 0.7 & 2041 & 2053 & 2074 & & 0.7 & 4.69 & 4.6 & 4.44 & \\
\hline
\end{tabular}

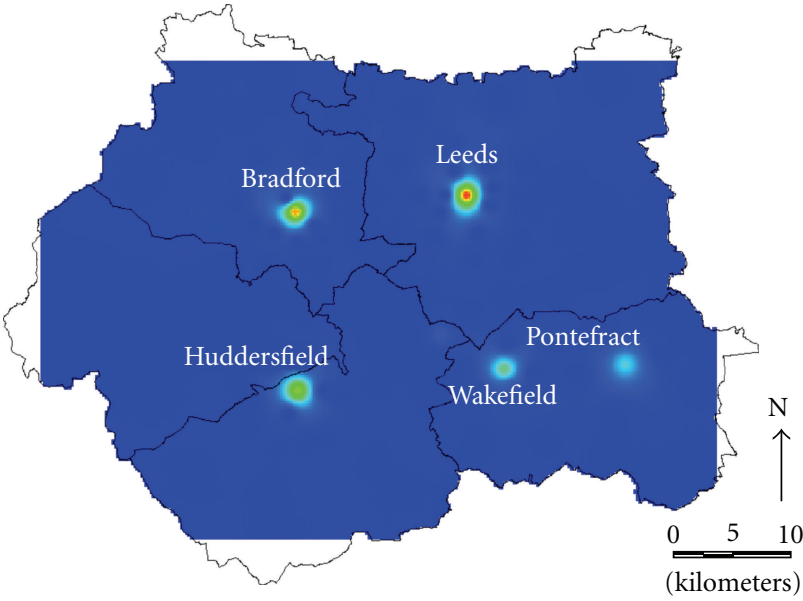

$$
\begin{aligned}
& \text { Profit }(\mathfrak{E}) \square 10,100,000 \\
& \square 20,200,000 \square 5,050,000 \\
& 15,150,000 \\
& \square \quad 5
\end{aligned}
$$

Figure 3: Interpolated sales surface of the simulation $\alpha=1.05, \beta=$ 0.2 applied to West Yorkshire, UK (cities and towns are indicated by place name).

in relation to the parameter beta. The entropy of dispersion is calculated as

$$
\mathrm{EoD}=-\sum_{j} W_{j} \log w_{j}
$$

where $w_{j}$ is the floorspace share in zone $j$, that is, $w_{j}=$ $W_{j} / \sum_{k} W_{k}$.

This statistic has been widely adopted in the context of information theory and elsewhere and has the well-known property of producing higher values for more dispersed distributions (high entropy states). For example, in Figure 2 the combination $(1.5,0.2)$ has an $\mathrm{EoD}$ value of 0.42 , while the combination $(1.05,1.0)$ has an EoD value of 4.68 . We used data from a national inventory of petrol stations [30] to calculate $W_{j}$ as the number of petrol station pumps in each zone. These data yielded an EoD of 4.52.

The average distance travelled by consumers is problematic since we did not have access to primary data on trips to petrol stations. Therefore we accessed a dataset deposited at the Economic and Social Data Service reporting the research of Ning and Haining [31], in which the origin and destination points from a survey of 450 petrol consumers were collected. The average straight-line distance of these trips was calculated to be $2.36 \mathrm{~km}$.

Therefore the problem is to try and identify the combination of parameters in the model which gives an EoD of 4.52 and an average trip length of 2.36. This combination was found using a simple mesh of parameter values, in which the granularity of the mesh is increased at successive iterations, as shown in Table 1. In the first pass, we begin with the combination of beta $=(0.2,0.5,1.0)$ and alpha $=$ $(1.0,1.05,1.2,1.5)$. The required distance of $2.36 \mathrm{~km}$ and EoD of 4.52 is indicated within the range of $0.5-1.0$ for beta and 1.0-1.05 for alpha. These ranges are therefore expanded 


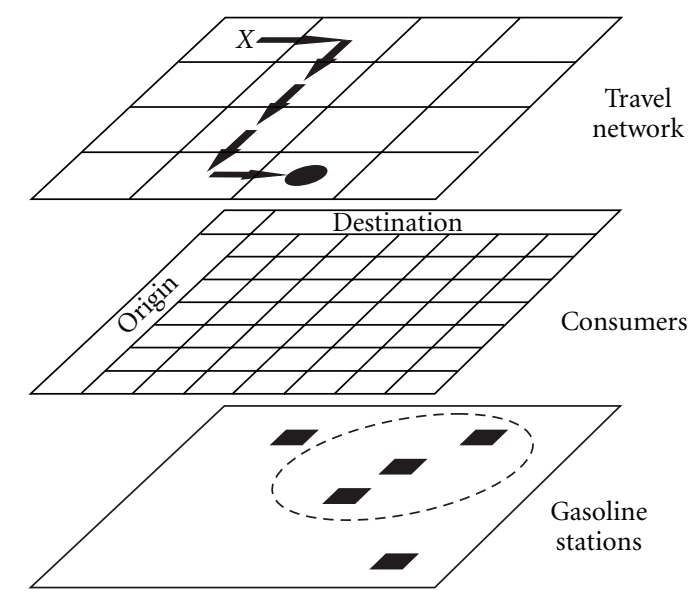

Figure 4: Diagrammatic representation of the different layers within the model.

in the second pass of the model, and the process is then repeated. Eventually we arrived at a combination of alpha $=$ 1.008 and beta $=0.634$ (see Table 1$)$.

\section{An Agent-Based Model of Retail Dynamics}

In this section of the paper, we introduce an agent-based model of retail market dynamics. This model is driven by a process of price competition between retail agents. It is shown that if the mechanism of price competition is replaced with a mechanism of floorspace adjustment, then the model can exhibit identical behaviour to the equilibrium-seeking model of Section 2. We then explore the effect of combining both price and floorspace adjustments within the same agent-based retail model.

3.1. Agent-Based Model, Versions 1 and 2. An agent-based model of retail dynamics was proposed by Heppenstall et al. [24], with a petrol market example. The authors considered spatial price competition as a key dynamic in the marketplace. In part, this view was predicated on an understanding that petrol station managers are strongly motivated by simple locational rules in relation to their competitors-for example, the "Pricewatch" campaign in which a multinational retailer commits to match the lowest prices of its competitors within a specified distance of each of its outlets. In terms of market simulation, such rules were found to be inadequate, as the individual retailers will simply compete each others prices down to zero. Therefore a mechanism was introduced in which consumers are sensitive to both price and distance, but retailers also have to meet certain costs of supply. The "rules" by which agents adjust their prices are now related to profitability. If costs exceed revenues so that profits are negative, then retailers will increase prices to redress the balance. On the other hand, if profits are made then retailers will reduce prices to attract more customers and boost market share.

A diagrammatic overview of the model is presented in Figure 4. The model is divided into three interlinked layers; the petrol station (here, agents are represented as individual stations), the consumer network (a representation of the location, size, and behaviour of a population), and the travel network (movement of the population around the grid). From examination of available literature and real data, this architecture was chosen to reflect the different layers seen within the real life system. This model has been applied to illustrate differential price setting between urban and rural areas [24], spatial diffusion of price shocks across a retail network [25], and a genetic algorithm was applied to derive agent rules and parameters from a pool of alternatives [26].

The agent-based retail model is based on the following behavioural equations [24]:

$$
\begin{gathered}
\hat{S}_{i j}^{m}=\delta_{j}^{m} \exp \left[-\beta d_{i j}-\lambda p_{j}^{m}\right], \\
S_{i j}^{m}=\frac{\widehat{S}_{i j}^{m}}{\sum_{j} \widehat{S}_{i j}^{m}} H_{i} F_{m},
\end{gathered}
$$

where

(i) $S_{i j}^{m}$ is the amount of fuel $m$ sold by garage $j$ to ward $i$,

(ii) $\delta_{j}^{m}$ is 1 where garage $j$ sells fuel $m$ and 0 otherwise,

(iii) $d_{i j}$ is the distance between ward $i$ and garage $j$,

(iv) $p_{j}^{m}$ is the price of fuel $m$ at garage $j$,

(v) $H_{i}$ is the number of households within the ward $i$,

(vi) $F^{m}$ is the amount of fuel of type $m$ required per household per day.

If we assume that petrol prices are equal at any location then the price terms cancel out; thus if we further assume that there is a single fuel type, but that rather than a zeroone relationship for provision, that customers are attracted by the level of provision (floorspace) of garage $j$, then this model becomes equivalent to the spatial interaction model (1). Since prices are now equalised, agents are no longer able to compete on this basis, so what happens if we substitute an adjustment in which floorspace rather than prices are adjusted to profitability? Not surprisingly, the whole model system now exhibits identical behaviour to the equilibriumseeking model of Section 2. This has been demonstrated computationally across the range of simulations presented earlier, amongst others. See Figure 5, for example, which shows two identical solutions for the pivot values $(\alpha=1.008$, $\beta=0.634$ ) which are derived for the floorspace adjustment model and the agent-based model, respectively.

To summarise, the agent-based model can be made equivalent to the equilibrium model if we make the following assumptions.

(i) There are no variations in prices between locations.

(ii) Destination attractiveness is related to provision/ floorspace.

(iii) There is a single, homogenous fuel type.

(iv) Floorspace adjusts in relation to agent profitability from an initially uniform distribution. 
3.2. Agent-Based Model: Version 3. One of the appealing features of the "revised" agent-based model at Section 3.1 is that it seems to provide an obvious platform for hybridisation of the two dynamic processes. By combining adjustments in both prices and floorspace, we can easily create a simulation in which retail agents compete with one another through both means. In our early experiments, we simply assume a parallel adjustment:

$$
\begin{aligned}
& W_{j}(t+1)=W_{j}(t) *\left[1+\frac{\varepsilon^{1}\left(D_{j}(t)-C_{j}(t)\right)}{C_{j}(t)}\right], \\
& p_{j}(t+1)=p_{j}(t) *\left[1+\frac{\varepsilon^{2}\left(D_{j}(t)-C_{j}(t)\right)}{C_{j}(t)}\right],
\end{aligned}
$$

where $\varepsilon^{1}$ is now a parameter which controls the speed of adjustment in floorspace; and $\varepsilon^{2}$ controls the speed of adjustment in relation to prices.

For the purpose of the simulation, we adopt a lambda value of 0.7 [30].

Now of course we find that the rates of change $\left(\varepsilon^{1}\right.$, $\left.\varepsilon^{2}\right)$ do not simply have the role of guaranteeing smooth progress to a stable equilibrium, but have a fundamental impact on the nature of that equilibrium. In the special case where $\varepsilon^{1}=0.05, \varepsilon^{2}=0$, then the new model is still equivalent to the original equilibrium-seeking version, as long as all prices are initially set to be equal. However other parameter combinations will now generate a variety of behavioural and spatial combinations. Some examples are shown in Figure 6. This work in itself has echoes of experiments undertaken in relation to rents and prices by Birkin and Wilson [32]. However in Section 4 we argue that the new agent framework has the capability to expose a wide new spectrum of applications.

\section{Extended Applications of a Dynamic Retail Model}

4.1. Discontinuous Evolution. One of the most obvious weaknesses of established approaches to equilibrium modelling is that smooth change in provision is generally assumed in relation to underlying profitability (cf. (7)). In practice, although changes in price may be relatively continuous, changes in floorspace are rarely as subtle. Having said that, even petrol companies will rarely adjust prices by increments of $0.1 \mathrm{p}$, the theoretical minimum.

Discontinuous adjustments are quite easy to handle in the agent-based simulation. In the next example, we conceive a situation in which an individual "petrol station" has a floorspace of 100 square metres and that each station owner or manager confronts three choices at each time stepmaintain operations, close a station, or add a new one at either the existing location or a new location. The probability of each event is related to operational profitability at that time, according to the rules which are shown in Table 2. For example, if a petrol station makes a very modest daily profit of $£ 100$, then there is a $40 \%$ chance that the operator will close it and seek a better location.
TABLE 2: Transition probabilities: discontinuous evolution.

\begin{tabular}{lccc}
\hline Profit & Prob close & Prob stay & Prob add \\
\hline (pence per day) & & & \\
100 & 0.8 & 0.2 & 0. \\
5000 & 0.7 & 0.25 & 0.05 \\
10000 & 0.4 & 0.5 & 0.1 \\
25000 & 0.1 & 0.8 & 0.1 \\
50000 & 0.1 & 0.6 & 0.3 \\
75000 & 0.0 & 0.4 & 0.6 \\
100000 & 0. & 0.2 & 0.8 \\
\hline
\end{tabular}

Here we can see that for the pivot case $\left(\varepsilon^{1}=0.05\right.$, $\left.\varepsilon^{2}=0.2\right)$ the discontinuous model is structurally similar to the base case as shown in Figure 7.

However one of the main differences appears to be the "disappearance" of the smaller peaks. The probability that low-profit-making stations will stay open has been continually reduced; hence many of these weaker stations have been eliminated. Conversely, the stronger stations have thrived and with fewer competitors they have made substantially more profit (the peaks in the nondiscontinuous simulations are around $£ 1000$; in the discontinuous, they are $£ 2000-£ 2500$ ). Those stations that are particularly successful are allowed to expand; this in turn (with the removal of smaller competitors) has allowed these stations to increase their levels of profit.

The associated time series evolution of the discontinuous change model is illustrated in Table 3.

Note that of course one of the characteristics of the discontinuous evolution approach is that there is a chance that profitable stations can be closed. For example, one station was making a consistent profit of $\mathfrak{E} 500$ or more right up until day 150, but still ended up being closed. On the other hand, once floorspace is eliminated in the continuous change simulations (what Harris and Wilson refer to as No Development Possible (NDP) states) then no further development will ever be possible. Such locations can easily be "recolonised" in the discontinuous evolution model. These ideas are illustrated in Figure 8, where a portfolio of locations is compared from the two models. On the left hand side (continuous change) we see two stations without development, one of which never established any basis for trade, the other is initially profitable but gradually succumbs to competitive pressures before being eliminated. On the right hand side, by contrast, two stations are building business quite smoothly before suddenly closing; while another bursts back to life after an extended lull. Of course the possibilities for further refinement of the underlying decision rules is quite extensive.

The fact that local geographies are strongly conditioned by specific decisions has always been a conceptual difficulty for modellers. A typical example which has been quoted in the past is of the future development of Oxford being strongly conditioned by the decision of William Morris to build his car plant at Cowley. The representation of "lumpy" decision-making by agents at least provides some initial 


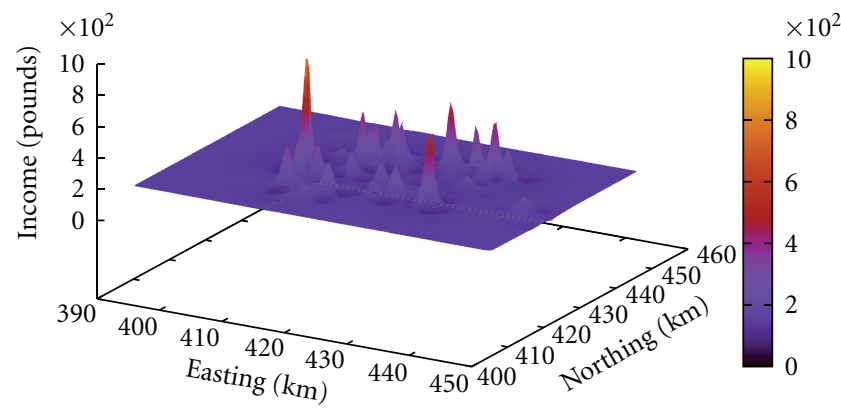

(a) Floorspace adjustment model

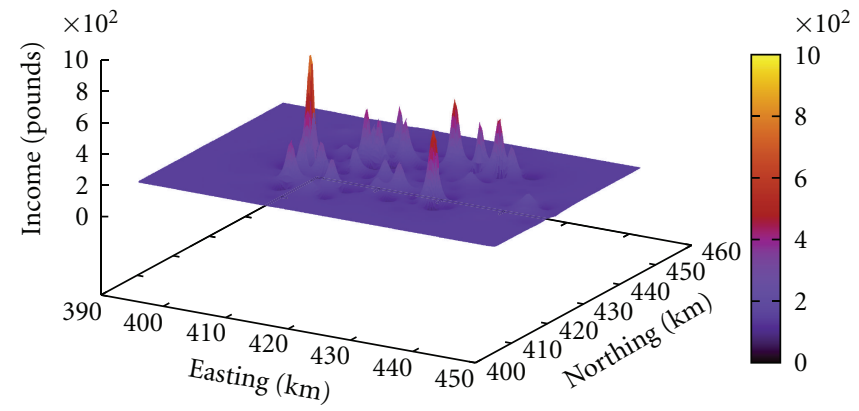

(b) Agent-based model

FIGURE 5: Equivalence of solutions from (a) floor adjustment model and (b) agent-based model with pivot parameter values.

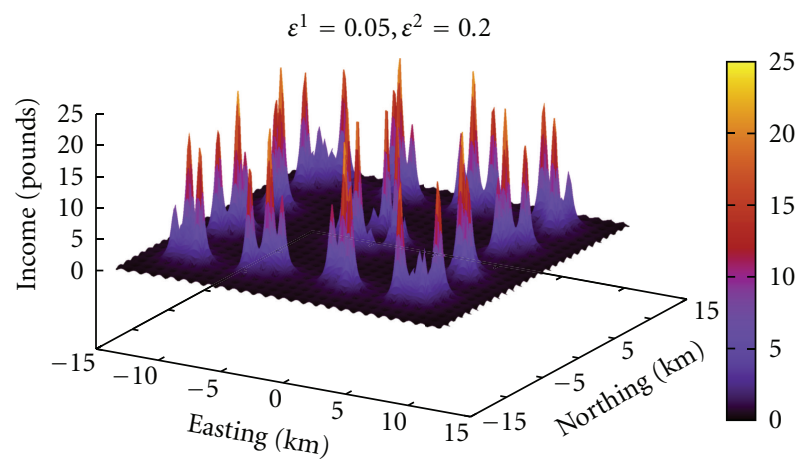

(a)

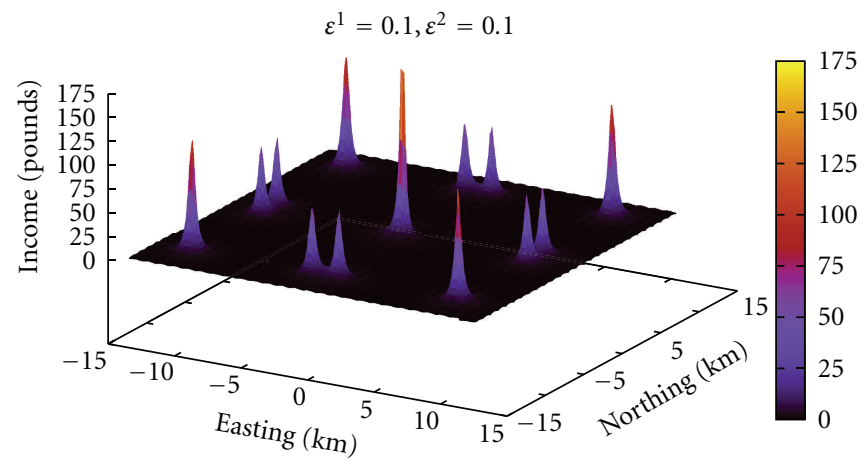

(b)

$\varepsilon^{1}=0.2, \varepsilon^{2}=0.05$

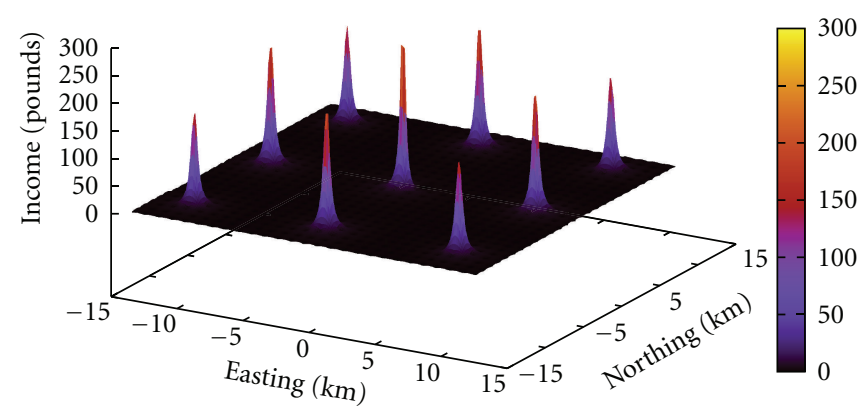

(c)

FIGURE 6: Variations in equilibrium spatial structure: price adjustment versus floorspace adjustment.

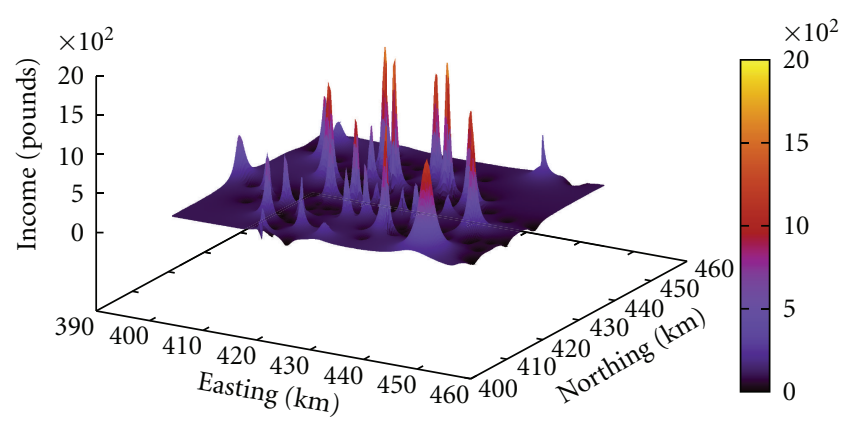

(a) Continuous profit change: Day 200

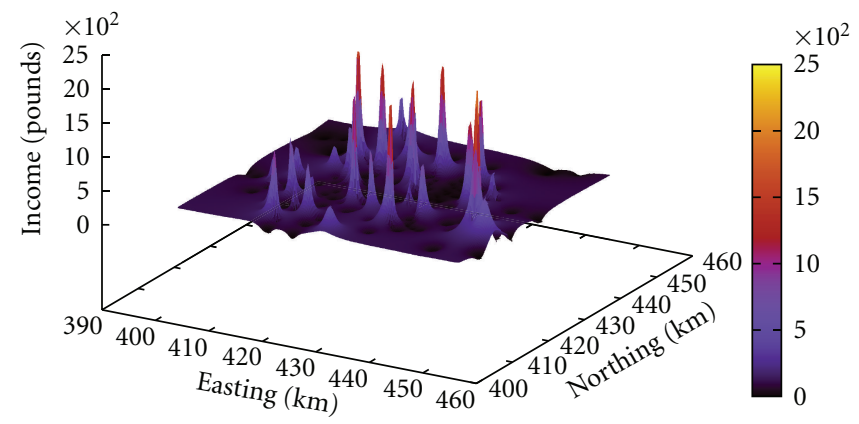

(b) Discontinuous profit change: Day 200

FIGURE 7: Comparison of spatial structure with (a) continuous and (b) discontinuous change. 


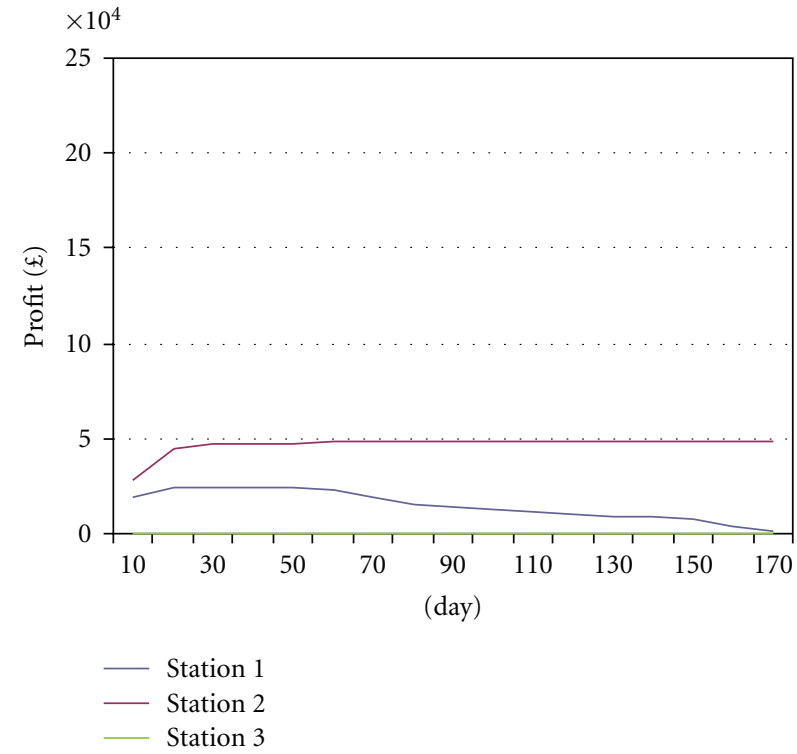

(a) Continuous

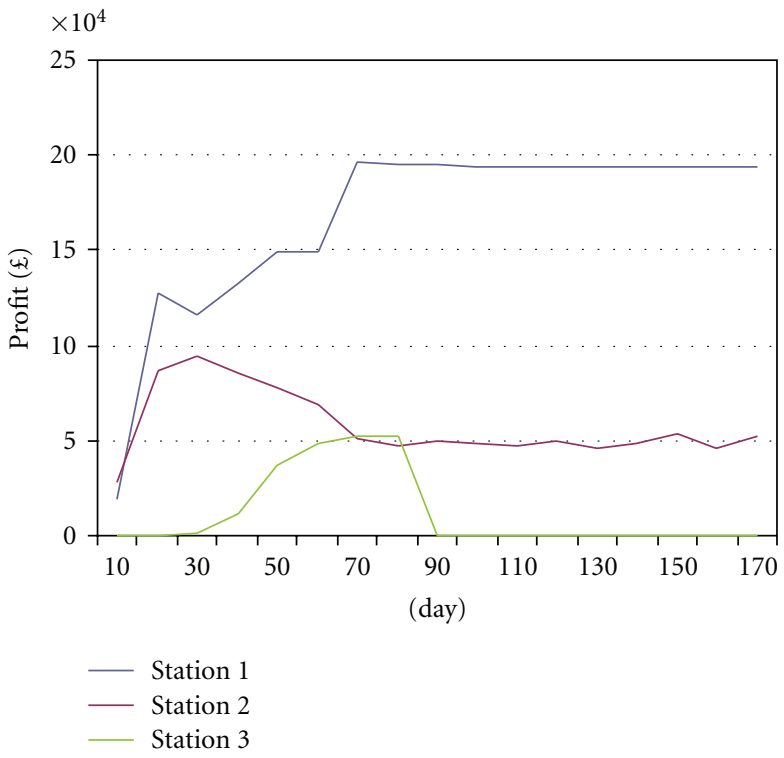

(b) Discontinuous

Figure 8: Comparison of selected station behaviour in (a) continuous and (b) discontinuous mode.

TABLE 3: Showing number of outlets that are open at selected intervals and the average amount of profit $(\mathfrak{E})$ per outlet.

\begin{tabular}{lcc}
\hline Time (day) & Stations open & Average profit $(\mathfrak{E})$ \\
\hline 1 & 260 & 43.25 \\
2 & 158 & 70.77 \\
3 & 96 & 120.94 \\
4 & 66 & 170.47 \\
5 & 53 & 211.67 \\
10 & 36 & 318.35 \\
50 & 28 & 418.81 \\
100 & 28 & 418.24 \\
150 & 28 & 425.78 \\
200 & 27 & 433.41 \\
\hline
\end{tabular}

insights and a counter to the problem of how to relate observed patterns to the historical evolution of a city system. It is worth noting further that the decisions implied by Table 2 are not completely rational-on occasions it is possible that a loss-making operation will decide to build its way out of trouble, and it is not impossible that such a strategy might succeed (especially in "high alpha" retail environments where scale yields disproportionate advantages).

Note that only a simple range of agent behaviours is represented here. Clearly more complex rules (e.g., only expand after three consecutive years of profit) could be considered. We might even consider some notion of capital accumulation by site owners, which would be another interesting direction to extend the models.

The threat of dysfunctional behaviour-in either the model, the system, or both-is never far away when discontinuous evolution is modelled. From the different behaviour exhibited in Figure 8, we could envisage over a sufficiently long period of time situations in which a site initially grows, becomes unprofitable, "crashes", receives reinvestment, and thrives again. This could be analogous to the fortunes of certain suburban or edge of town retail centres. There is a link to previous work, in particular speculations relating to catastrophe theory and bifurcation [13] and links to ecological modulations of population development (e.g., May, 1979), albeit that in those simulations discontinuous change in relation to smooth parameter shifts is usually the norm.

4.2. Nonequilibrium Dynamics. One way in which we can envisage nonequilibrium dynamics arising in our system is through agents responding too quickly to environmental change (cf. [13, 33]). A second possibility is to recognise that parameters themselves are actually never any more stable than the stock variables which are the focus of the simulation. A particularly good example of this relevant to the current case would be oil prices, for example, in the year to October 2008 oil prices fluctuated between $\$ 80$ and $\$ 140$ per barrel with a mean fluctuation between months of $\$ 10$ [34].

We introduced exogenous effects of this type into the model by adding a Gaussian random number with a specified standard deviation to the costToProduce variable (this parameter accounts for the price of crude oil) at every iteration. Gaussian random numbers follow a normal distribution with a known mean and standard deviation. Two sets of results are shown in Figures 9 and 10. In the first example (Figure 9) production costs are adjusted with fluctuation increments having a standard deviation of $£ 1$ per day. Two interesting features of this simulation are that the profit profiles tend to fluctuate in line with the underlying cost trend, even though the average profit levels still vary 


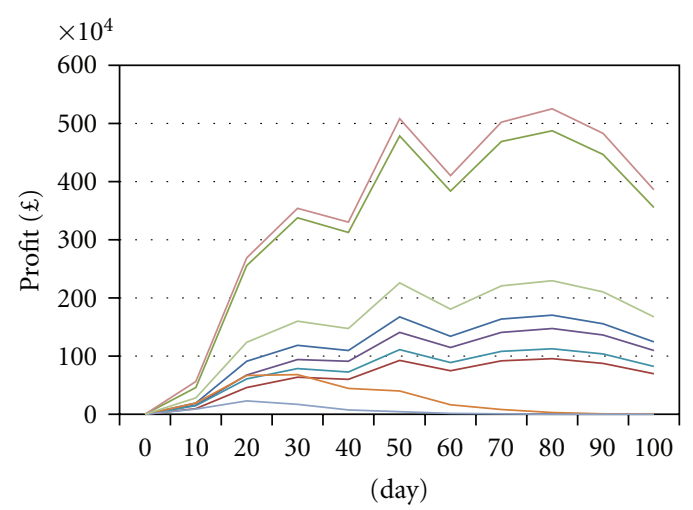

(a)

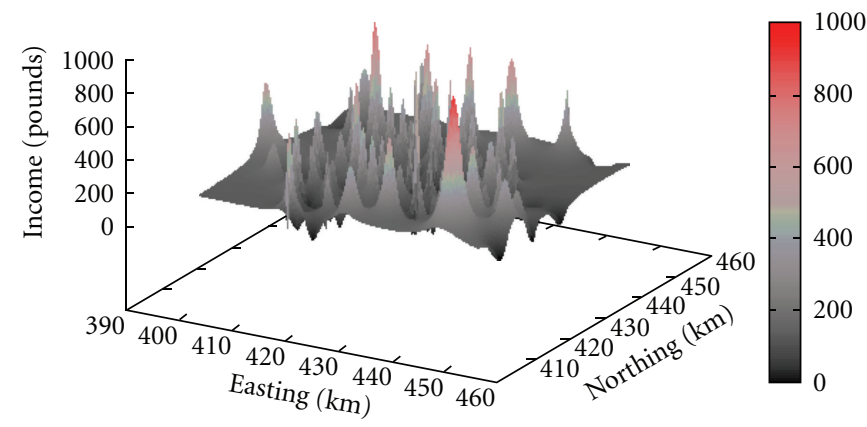

(b)

Figure 9: (a) Profit of selected stations plotted every 10 days; (b) profit surface at day 100.

by location. A second feature is that continuous changes in the cost to produce seems to keep the system, and its constituent retailers, in a persistent disequilibrium state. There is certainly no suggestion of profit convergence in Figure 9(a). Nevertheless, the disequilibrium profit surface at day 100 (Figure 9(b)) does not look qualitatively different to the equivalent outcomes from earlier simulations.

The second simulation (Figure 10) shows results with a production cost varying with a standard deviation of $\mathfrak{E} 3$. In this case we see further disequilibrium variations which are of sufficient magnitude to destabilise the system and change its character quite fundamentally. Only the largest outlets (in this case, a single "city centre" retailer) are sufficiently robust to withstand the impact of persistent cost shocks. The overall profit surface (Figure 10) is now quite different to that of Figure 9.

Even this model simplifies in at least two important respects: we ignore the effects of other cost components, like tax and distribution, and we ignore the possibility that the change in crude oil prices is factored directly into pump prices. Nevertheless the simulation makes the important point that retail floorspaces are a "slow" dynamic in relation to other factors such as taxation and price. Therefore, dynamic disequilibrium is much more likely to be the rule rather than the exception as floorspace continually adjusts to cost and price variations. Note also that demand patterns are affected by the distribution of population which is also conditioned by slow dynamics in relation to migration and other demographic processes. We return to the linkage between different model subsystems in Section 4.3 below.

4.3. Introduction of New Decision Variables: The Example of Land Rents. In our earlier discussion (Section 3.2) we observed the effect of introducing a dynamic price adjustment mechanism alongside the more conventional floorspace adjustment of Harris and Wilson. We showed how alternative solutions could be arrived at through variations in the relative importance of these mechanisms. In the final simulation of this paper, we consider the introduction of a new class of agents representing land owners. The objective of the land owners is to extract as much rent as they can from each parcel of land. Their behaviour can be described in terms of the following rules.

(i) At the outset, land is offered to retailers at no charge.

(ii) As land-owners observe retailers enjoying profits from the development of their land, the rents for each parcel are steadily increased.

(iii) If no profit is possible from retail activity, the rents fall back to zero.

This behaviour can be expressed in terms of two relatively straightforward modifications to the model equations. Whereas costs were once a simple linear multiple of floorspace, now we have

$$
C_{j}(t)=k W_{j}(t)+r_{j}(t),
$$

where $r_{j}(t)$ is the rent from a parcel of land at location $j$, time $t$; and

$$
r_{j}(t)=r_{j}(t)+\varepsilon^{3}\left(D_{j}(t)-C_{j}(t)\right) .
$$

The equilibrium results from a simulation with pivot values of $\alpha=1.008, \beta=0.634, \varepsilon^{1}=0.1$, and a new adjustment rate of $\varepsilon^{3}=0.1$, are shown in Figure 11. In structural terms the outcome is very similar to the previous version of the simulation with zero rents (Figure 5). In a sense, there is a suggestion here that profits may have been displaced (from retailers to land-owners). What can also be seen however is a further element of distortion in which the peaks are no longer distributed identically in space. There is a suggestion here perhaps of a "game theoretic" component to revenue maximisation in which the strategies adopted by the various agents might affect their long-term success and prosperity. There is some resonance here with our previous observations about the arbitrary impact of decisions by entrepreneurs and land owners on long-term system dynamics and behaviour.

The introduction of land rents may be thought of as a general illustration of the influence of third party agents on spatial development processes. For example, the influence of suppliers (in setting commodity prices) or regulators (in deciding taxes and duties) might be considered within the 


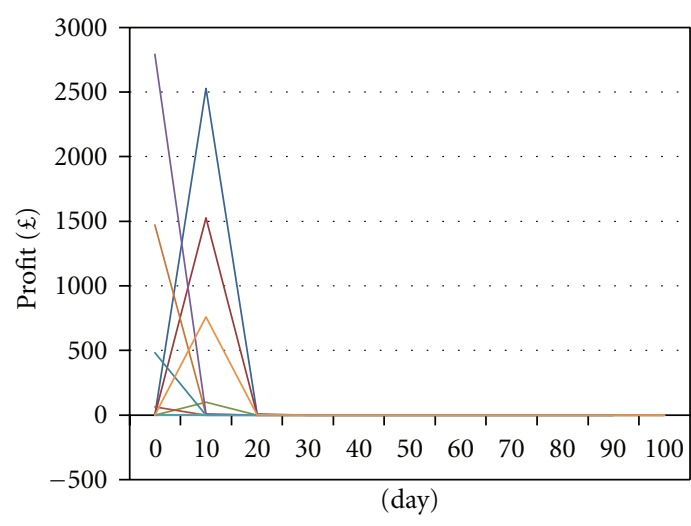

(a)

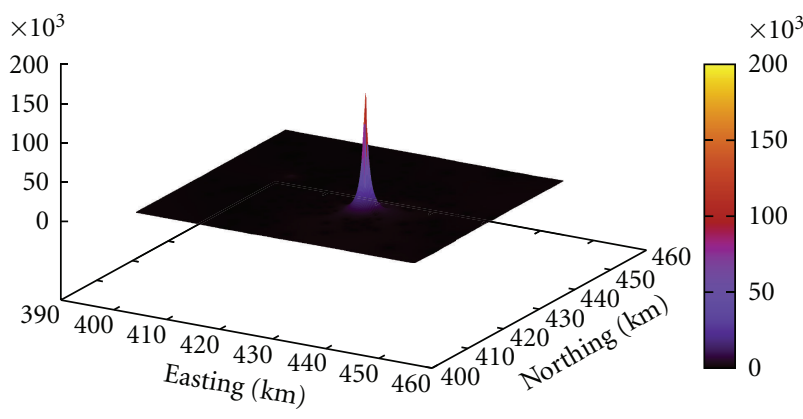

(b)

Figure 10: (a) Profit of selected stations plotted every 10 days (note: the station with the highest level of profit has been omitted to see the behaviour of the others); (b) profit surface at day 100.

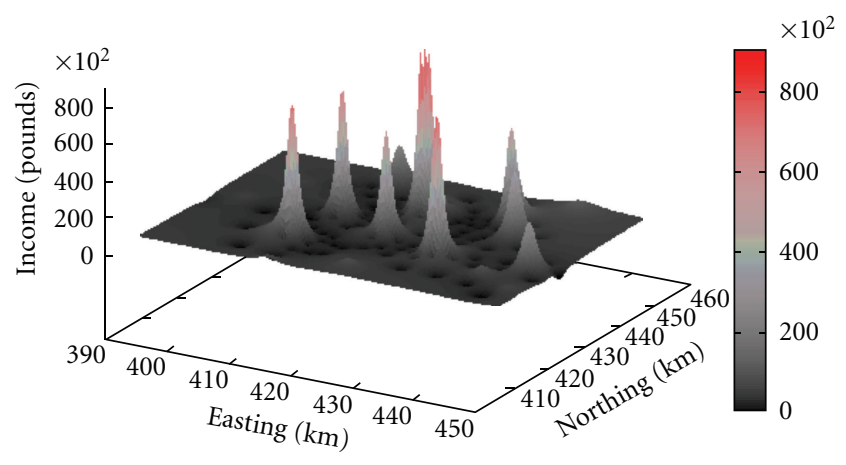

FIgURE 11: An equilibrium distribution of land rents.

same general framework. Nevertheless land rents are also distinctive in their spatial composition. The introduction of rents may be supposed to be uniquely interesting for spaceconsuming activities like housing and agriculture. Specific consideration of urban land markets may also provide a connecting mechanism for more comprehensive models of urban dynamics and land use, in which land rents might be used as a regulatory device in the competition for locations between housing, retail, industry, transport, and other activity types.

\section{Discussion/Conclusions}

Many papers have been published since Harris and Wilson's study of equilibrium urban dynamics in 1978. Nevertheless, the paper remains a classic in terms of both the enduring importance of the issues which are addressed, and further research which has been inspired from this initial perspective-what Clarke and Wilson [8] refer to in the title of another paper as "The progress of a research programme". The attempt which we offer in the current paper to integrate this earlier research with the methods of agent-based modelling is therefore fully justified by both the importance of this earlier research, and by the exciting potential of contemporary techniques.
The suggestion that agent-based representations provide an alternative means to represent equilibrium-seeking behaviour in dynamic retail environments which is for all purposes equivalent to the earlier aggregate approaches of Harris-Wilson and others is an important starting point. We have demonstrated that this switch allows new kinds of behaviours, which are themselves much more "realistic", to be incorporated with relative ease. This has been illustrated with reference to model scenarios reflecting dynamic price adjustments, discontinuous evolution, environmental interactions, and the influence of third party decisionmakers (land owners). It is also worth reflecting, however, that when adherents of new approaches using agents talk enthusiastically about radically new concepts such as the complexity of compound systems with simple behaviour and the emergence of new spatial structures with continuous parametric evolution (e.g., [35]), that these sentiments resonate so strongly with the earlier ideas of bifurcation in spatial systems, and even the invocation of catastrophe theory to provide insights into discontinuities in urban spatial structure and behaviour [13].

It is important to recognise that a shift in perspective does not necessarily provide an instant solution to all of the major intellectual challenges of social simulation. Indeed we have seen that many important questions remain open, for example, what factors actually determine the behaviour of agents in real world systems; how can the parameters of complex models be determined for real systems; what is the best way to simulate cityscapes as the outcome of a process of historical evolution; does complexity in models fairly reflect the complexity of urban systems - to paraphrase Andrew Sayer [36], are we getting a better understanding of cities, or just a set of tangential model-based representations? At heart, all of these questions relate in some degree to the challenge of validation, which is surely the next great challenge for simulation modelling [37].

The modelling themes introduced in this paper represent an early contribution to the project of Generative Social Simulation $[28,38]$. This work aspires to the construction of agent-based representations of social processes, which 
incorporate rich and detailed representations of characteristics at the microscale, within a framework of calibration, verification and validation of real systems. A successful outcome would do much to elevate agent-based modelling from the realm of pedagogic toy to major research weapon.

\section{References}

[1] D. Huff, "Defining and estimating a trading area," Journal of Marketing, vol. 28, pp. 34-38, 1963.

[2] A. G. Wilson, "A statistical theory of spatial distribution models," Transportation Research, vol. 1, no. 3, pp. 253-269, 1967.

[3] A. G. Wilson, Entropy in Urban and Regional Modelling, Pion, London, UK, 1970.

[4] M. Birkin and G. Clarke, "Spatial interaction in geography," Geography Review, vol. 4, no. 5, pp. 16-21, 1991.

[5] M. Birkin, G. P. Clarke, M. Clarke, and A. G. Wilson, Intelligent GIS, Geoinformation, Cambridge, Mass, USA, 1996.

[6] M. Birkin, G. P. Clarke, and M. Clarke, Retail Geography and Intelligent Network Planning, John Wiley \& Sons, Chichester, UK, 2002.

[7] B. Harris and A. G. Wilson, "Equilibrium values and dynamics of attractiveness terms in production-constrained spatial interaction models," Environment and Planning A, vol. 10, pp. 371-388, 1978.

[8] M. Clarke and A. G. Wilson, "The dynamics of urban spatial structure: progress and problems," Journal of Regional Science, vol. 23, no. 1, pp. 1-18, 1983.

[9] M. Clarke and A. G. Wilson, "The dynamics of urban spatial structure: the progress of a research programme," Transactions of the Institute of British Geographers, vol. 10, no. 4, pp. 427451, 1985.

[10] M. Birkin and A. G. Wilson, "Industrial location models 1: a review and an integrating framework," Environment \& Planning A, vol. 18, no. 2, pp. 175-205, 1986.

[11] M. Birkin and A. G. Wilson, "Industrial location models 2: Weber, Palander, Hotelling, and extensions within a new framework," Environment \& Planning A, vol. 18, no. 3, pp. 293-306, 1986.

[12] A. G. Wilson and M. Birkin, "Dynamic models of agricultural location in a spatial interaction framework," Geographical Analysis, vol. 19, no. 1, pp. 31-56, 1987.

[13] A. G. Wilson, Catastrophe Theory and Bifurcation: Applications to Urban and Regional Systems, Croom Helm, London, UK, 1981.

[14] A. G. Wilson and M. J. Oulton, "The corner-shop to supermarket transition in retailing: the beginnings of empirical evidence (Nottingham, UK)," Environment \& Planning A, vol. 15, no. 2, pp. 265-274, 1983.

[15] G. P. Clarke and A. G. Wilson, "Combining theoretical and empirical research in retail location analysis," Working Paper 468, School of Geography, University of Leeds, 1986.

[16] M. Wooldridge and N. R. Jennings, "Intelligent agents: theory and practice," Knowledge Engineering Review, vol. 10, no. 2, pp. 115-152, 1998.

[17] R. Axtell, "Why agents? On the varied motivations for agent computing in the social science," CSED Working Paper 17, 2000, http://www.brookings.edu/es/dynamics/papers/agents/ agents.htm.

[18] K. Nagel, D. E. Wolf, P. Wagner, and P. Simon, "Two-lane traffic rules for cellular automata: a systematic approach," Physical Review E, vol. 58, no. 2, pp. 1425-1437, 1998.
[19] N. M. Ferguson, D. A. T. Cummings, S. Cauchemez et al., "Strategies for containing an emerging influenza pandemic in Southeast Asia," Nature, vol. 437, no. 7056, pp. 209-214, 2005.

[20] W. B. Arthur, "Complexity and the economy," Science, vol. 284, no. 5411, pp. 107-109, 1999.

[21] L. Tesfatsion and K. L. Judd, Handbook of Computational Economics, Volume 2: Agent-Based Computational Economics, North-Holland, Amsterdam, The Netherlands, 2006.

[22] D. Helbing, L. Buzna, A. Johansson, and T. Werner, "Selforganized pedestrian crowd dynamics: experiments, simulations, and design solutions," Transportation Science, vol. 39, no. 1, pp. 1-24, 2005.

[23] M. Batty, Cities and Complexity: Understanding Cities with Cellular Automata, Agent-Based Models, and Fractals, MIT Press, Cambridge, Mass, USA, 2007.

[24] A. J. Heppenstall, A. J. Evans, and M. H. Birkin, "A hybrid multi-agent/spatial interaction model system for petrol price setting," Transactions in GIS, vol. 9, no. 1, pp. 35-51, 2005.

[25] A. J. Heppenstall, A. J. Evans, and M. Birkin, "Application of multi-agent systems to modelling a dynamic, locally interacting retail market," Journal of Artificial Societies and Social Simulation, vol. 9, no. 3, 2006.

[26] A. J. Heppenstall, A. J. Evans, and M. H. Birkin, "Genetic algorithm optimisation of an agent-based model for simulating a retail market," Environment and Planning B, vol. 34, no. 6, pp. 1051-1070, 2007.

[27] S. E. Page, "Agent based models," in The New Palgrave Dictionary of Economics, Palgrave Macmillan, New York, NY, USA, 2nd edition, 2008.

[28] M. Batty, "Generative social science: a challenge," Environment and Planning B, vol. 35, no. 2, pp. 191-194, 2008.

[29] Office for National Statistics, General Household Survey 2007, HMSO, London, UK, 2008.

[30] A. J. Heppenstall, Application of hybrid intelligent agents to modelling a dynamic locally interacting retail model, Ph.D. thesis, University of Leeds, 2005.

[31] X. Ning and R. Haining, "Spatial pricing in interdependent markets: a case study of petrol retailing in Sheffield," Environment and Planning A, vol. 35, no. 12, pp. 2131-2160, 2003.

[32] M. Birkin and A. G. Wilson, "Some properties of spatialstructural- economic-dynamic urban models," in Progress in the Dynamic Analysis of Spatial Systems, J. Hauer, H. Timmermans, and N. Wrigley, Eds., pp. 184-200, Reidel, 1989.

[33] R. May, "Bifurcations and dynamic complexity in ecological systems," Annals of the New York Academy of Sciences, vol. 316, pp. 517-529, 1979.

[34] WTRG Economics, April 2009, http://www.wtrg.com/prices .htm.

[35] J. Epstein and R. Axtell, Growing Artificial Societies, Brookings Institution, 1996.

[36] R. A. Sayer, "Understanding urban models versus understanding cities," Environment and Planning A, vol. 11, no. 8, pp. 853$862,1979$.

[37] D. O'Sullivan, “Geographical information science: agentbased models," Progress in Human Geography, vol. 32, no. 4, pp. 541-550, 2008.

[38] J. Epstein, Generative Social Science: Studies in Agent-Based Computational Modelling, Princeton University Press, Princeton, NJ, USA, 2007. 


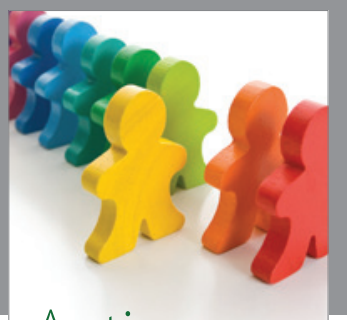

Autism

Research and Treatment
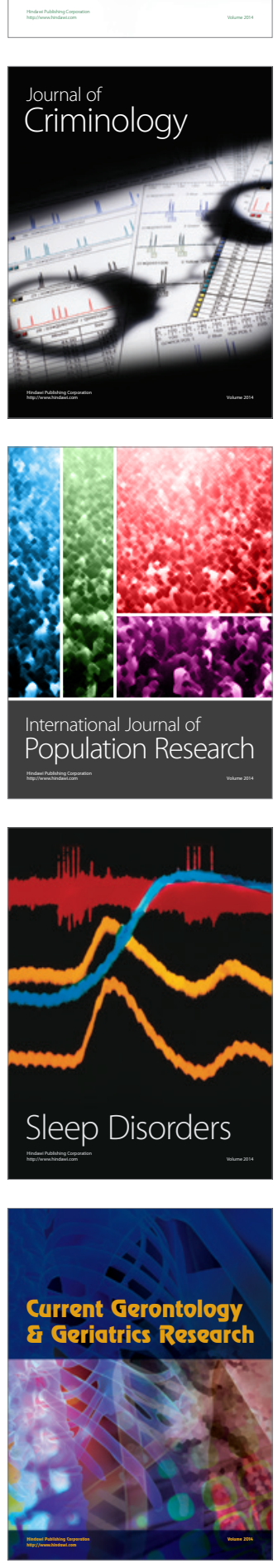
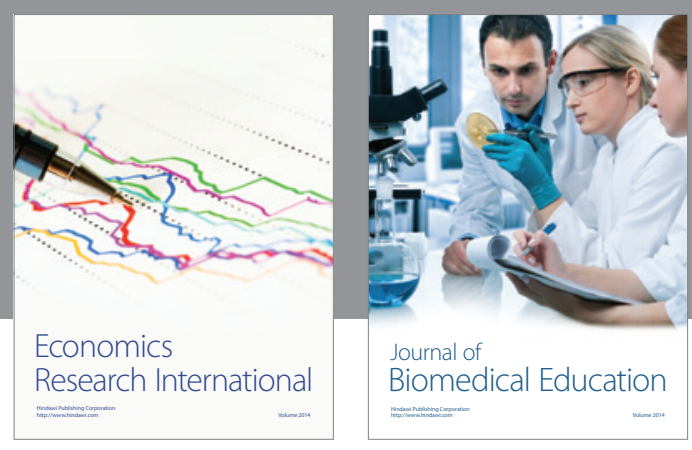

Journal of

Biomedical Education

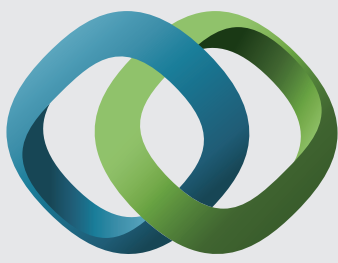

\section{Hindawi}

Submit your manuscripts at

http://www.hindawi.com
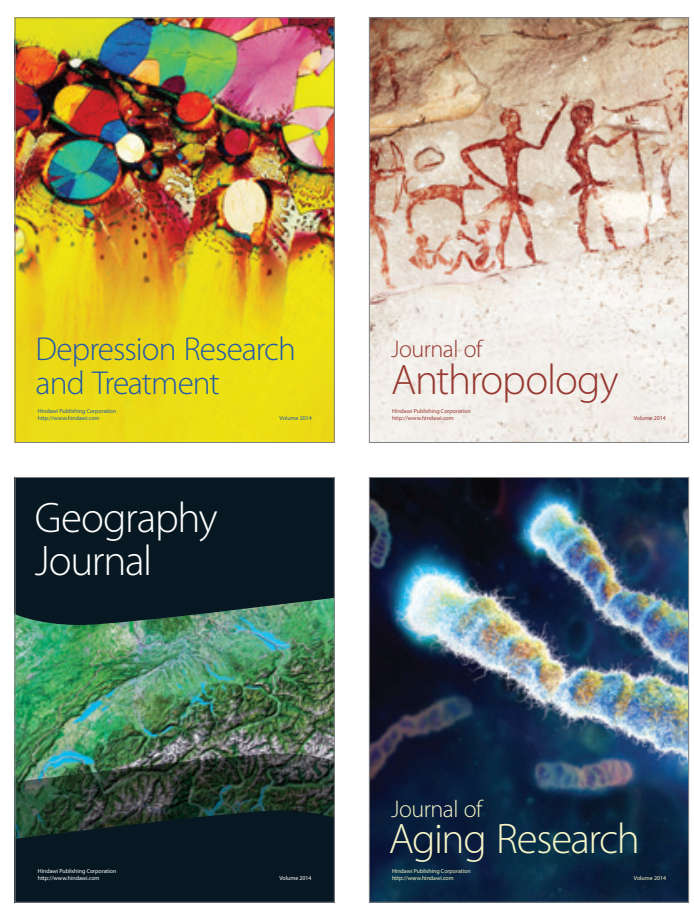

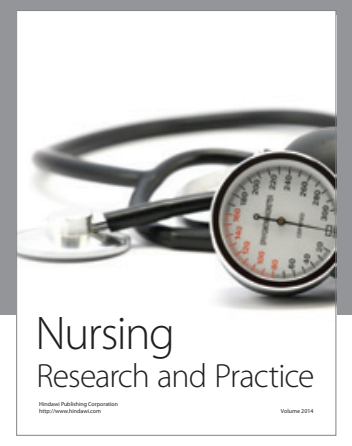

Nursing

Research and Practice

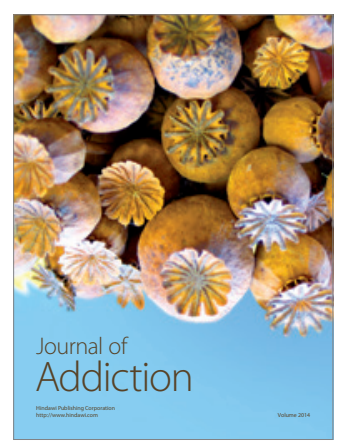

Child Development

Research

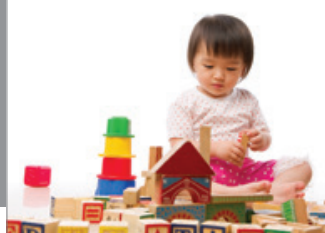

迥
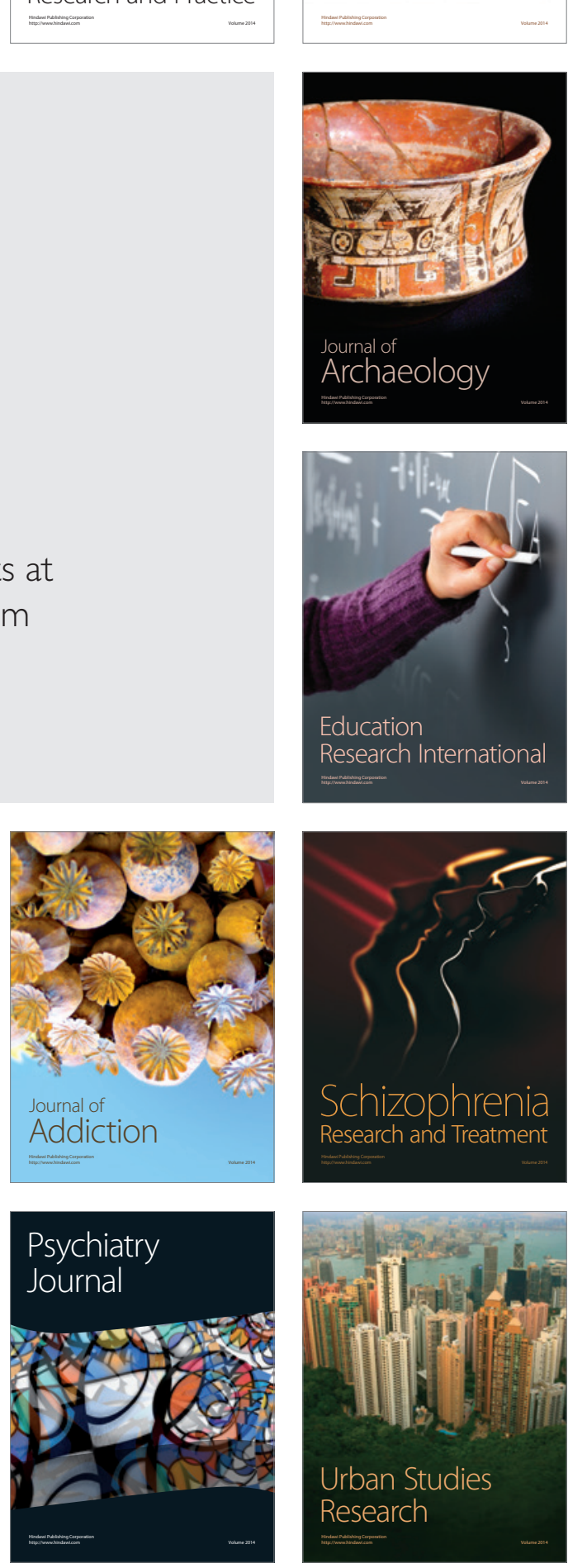